\title{
Novel Use of a Pyrenomycetous Mycoparasite for Management of Fusarium Wilt of Watermelon
}

\author{
R. M. Harveson and J. W. Kimbrough, Department of Plant Pathology, University of Florida, Gainesville 32611; \\ and D. L. Hopkins, Mid-Florida Research and Education Center, Apopka, FL 32703
}

\begin{abstract}
Harveson, R. M., Kimbrough, J. W., and Hopkins, D. L. 2002. Novel use of a pyrenomycetous mycoparasite for management of Fusarium wilt of watermelon. Plant Dis. 86:1025-1030.

Fusarium wilt of watermelon, caused by Fusarium oxysporum f. sp. niveum, is a destructive disease that limits watermelon production in many areas of the world. The discovery of several pyrenomycetous ascomycetes occurring naturally in association with different formae speciales of $F$. oxysporum identified these fungi as potential biological control organisms for watermelon wilt. One such mycoparasitic isolate, identified as Sphaerodes retispora var. retispora, was chosen for biological control and ecological trials in the greenhouse. Four different methods to inoculate the mycoparasite were evaluated, three of which utilized the parasite encapsulated into sodium alginate pellets. The other method employed root-dipping plants with mycoparasite ascospore suspensions. Ecological factors also were investigated, including the ability of $S$. retispora var. retispora to colonize watermelon roots, and its ability to survive in soil over time and reduce propagules of $F$. oxysporum $\mathrm{f}$. sp. niveum. In the biological control studies, the use of the mycoparasite significantly reduced plant mortality and increased dry weights of watermelon plants after being challenged with $F$. oxysporum f. sp. niveum, compared with pathogen-inoculated controls. It appears that the incorporation of the parasite into alginate pellets in the planting mix at seeding may be the most practical method for future field evaluations of transplant-grown vegetable crops. In the ecological studies, the mycoparasite was recovered from infested soil after 9 months, but was only isolated from watermelon roots when applied in the presence of $F$. oxysporum. $S$. retispora var. retispora had no effect on $F$. oxysporum f. sp. niveum propagules after being applied to soils in the greenhouse.
\end{abstract}

Fusarium wilt and root rot diseases caused by formae speciales of Fusarium oxysporum include some of the oldest plant diseases described and are among the most severe and difficult to manage in the world. They cause significant economic losses to a wide range of plant species and occur on all plant families except Graminaceae (3). Most control methods available are either inefficient or difficult to apply. Fungicides are generally ineffective because of the location of the pathogen within the plant's vascular system. Soil fumigants can be useful, but disease control is erratic and fumigation often is cost-prohibitive. Furthermore, the beneficial effects of fumigation are generally only temporary and must be reapplied each season due to some formae speciales's ability to rapidly recolonize soils (26).

Corresponding author: R. M. Harveson

E-mail: rharveso2@unl.edu

Current address of R. M. Harveson: University of Nebraska, Panhandle Research and Extension Center, 4502 Ave. I, Scottsbluff 69361.

Florida Agricultural Experiment Station Journal Series No. R-07417.

Accepted for publication 20 May 2002.

Publication no. D-2002-0722-03R

(C) 2002 The American Phytopathological Society
Short-term crop rotation is of little value because $F$. oxysporum colonizes non-host plants and survives in soils for long periods as chlamydospores (28). Therefore, genetic resistance, when available, is often considered the most effective strategy for managing wilt diseases. However, this also can be problematic because the presence of different biological races necessitates the need for germ plasm containing multiple resistance genes.

Biological control of Fusarium wilts, in the form of suppressive soils, has been recognized for over 70 years $(4,16)$. Control in these soils is based on the exploitation of natural communities of microorganisms and generally is recognized to be among the best and most successful examples of biological control with microorganisms (5). Soils suppressive to $F$. oxysporum have been identified from and intensively studied in numerous locations throughout the world $(2-4,15,20,21)$. The majority of these soils tend to have different mechanisms of suppression; therefore, no one suppressive site would be consistent with any other in terms of generating standard suppressive-soil characteristics or control recommendations.

The wilt disease of watermelon, caused by $F$. oxysporum f. sp. niveum, is a major factor that limits production in many watermelon-growing areas (27). The disease was first reported in 1894 from Georgia and South Carolina (31) and, as with other wilt diseases induced by $F$. oxysporum, effective control measures for the watermelon wilt disease are limited. One of the few successful examples using biological control for this disease involved the induction of wilt-suppressive plots within a known wilt-conducive research field in Florida. These suppressive plots were created by monoculturing the moderately wiltresistant watermelon cv. Crimson Sweet for 4 to 7 years $(6,14,15)$. This is not a practical solution for all watermelon-growing areas; therefore, investigating alternative measures for managing watermelon wilt is warranted.

The idea for conducting the present study began while surveying Texas sugar beet fields and collecting pathogenic isolates of $F$. oxysporum f. sp. betae (12). In approximately 10 to $15 \%$ of the field isolations, a pyrenomycete was observed intermingled with the Fusarium cultures, and was later identified as Melanospora zamiae $(8,10)$. Its presence in the cultures also was observed to seriously affect growth and vigor of the $F$. oxysporum isolates $(8,10)$. Over the next several years, an additional five pyrenomycetous ascomycetes closely resembling $M$. zamiae were found in Florida in constant association with field populations of three distinct formae speciales of F. oxysporum $(8,10)$. Four of these isolates were identified as Sphaerodes retispora var. retispora and the fifth isolate proved to be a new report for Persiciospora moreaui $(9,10)$.

For several reasons, S. retispora var. retispora (isolate LE) was selected as the candidate for evaluating wilt disease reduction of watermelon in greenhouse tests. First, it sporulated readily in conjunction with the watermelon wilt isolate that was used in the tests. Second, of the six mycoparasites tested, isolate LE was the most aggressive in dual culture with the wilt pathogen and most effectively inhibited and reduced mycelial growth as measured in laboratory assays (11). Last, LE originally was isolated from diseased watermelon roots in association with $F$. oxysporum f. sp. niveum from one of the wilt-suppressive research plots in Leesburg, FL. This study was begun with the purpose of addressing the following objectives under greenhouse conditions: (i) to evaluate the pyrenomycetous mycoparasite S. retispora var. retispora as a biological control agent for Fusarium wilt of wa- 
termelon, (ii) to evaluate different methods for delivering the parasite into the infection court, and (iii) to evaluate the survival of colonize watermelon roots and to reduce $F$. oxysporum f. sp. niveum propagules in artificially infested soils.

\section{MATERIALS AND METHODS}

Preparation of sodium alginate pellets. Efforts to develop an optimal method of inoculating $S$. retispora var. retispora (isolate LE) began with the encapsulation of the mycoparasite into sodium alginate pellets (sodium salt of alginic acid, Acros Organics, NJ) using several modifications of previously reported studies by Fravel et al. (7) and Lewis and Papavizas (22,23). Our modified recipe consisted of an aqueous suspension of ascospores and hyphal fragments of isolate LE, wheat germ ground to pass through a $0.425-\mathrm{mm}$ screen, and sodium alginate $(2.6 \%)$. Sodium alginate was dissolved into distilled water $(10 \mathrm{~g} / 375 \mathrm{ml})$ on a stirring hot plate. Ground wheat germ was combined with distilled water $(20 \mathrm{~g} / 250 \mathrm{ml})$ in a separate flask. Both containers were autoclaved for $45 \mathrm{~min}$ and cooled to room temperature before adding the mycoparasite. Isolate LE was prepared by grinding 3-week-old

Table 1. Watermelon plant biomass after preliminary inoculation with Sphaerodes retispora var. retispora (isolate LE) followed by pathogen challenge from a microspore suspension of Fusarium oxysporum $\mathrm{f}$. sp niveum (inoculation method \#1)

\begin{tabular}{lccc}
\hline & \multicolumn{3}{c}{${\text { Plant dry weight }(\mathbf{g})^{\mathbf{y}}}$} \\
\cline { 2 - 4 } Treatment $^{\mathbf{z}}$ & Assay 1a & Assay 1b & Assay 2 \\
\hline Control & $4.26 \mathrm{ab}$ & $4.67 \mathrm{a}$ & $4.05 \mathrm{a}$ \\
LE control & $5.60 \mathrm{a}$ & $5.23 \mathrm{a}$ & $5.39 \mathrm{a}$ \\
LE + pathogen & $3.50 \mathrm{~b}$ & $5.10 \mathrm{a}$ & $3.65 \mathrm{~b}$ \\
Pathogen control & $1.12 \mathrm{c}$ & $0.55 \mathrm{~b}$ & $0.67 \mathrm{e}$ \\
96-14 + pathogen & $\ldots$ & $\ldots$ & $0.77 \mathrm{de}$ \\
LE/96-14 + pathogen & $\ldots$ & $\ldots$ & $1.93 \mathrm{c}$ \\
Pellets + pathogen & $\ldots$ & $\ldots$ & $0.91 \mathrm{de}$ \\
\hline
\end{tabular}

${ }^{y}$ Each value is the average of 18 plants ( 3 plants per replication). Means followed by the same letter in a column are not significantly different according to Fisher's least significant difference test $(P=$ 0.05 ). Assays $1 \mathrm{a}$ and $1 \mathrm{~b}$ use the same treatments, but are presented separately due to significant differences between repeated assays.

${ }^{\mathrm{z}}$ Watermelon plants (Charleston Gray) were grown for 6 weeks in a soil mix containing alginate pellets ( $5 \mathrm{~g} /$ liter) of either isolate LE, LE + nonpathogenic $F$. oxysporum isolate $96-14$, isolate $96-14$, agar (MA) cultures in sterile, distilled $\mathrm{mm}$ ) were used for each $200 \mathrm{ml}$ of water. The finished aqueous suspension was blended once again and consisted of 300 wheat germ slurry, and $100 \mathrm{ml}$ of macerated liquid fungal culture (8). The suspension was placed into an aspiration bottle and continuously stirred on a stir plate while dripping through a Pasteur CaCL of the suspension hit the $\mathrm{CaCL}_{2}$ solution, it was encapsulated into a spherical pellet. The calcium in the receiving solution suspension, and each pellet should contain equal amounts of sodium alginate, wheat germ, and fungal spores (7). Finished pellets were drained in a colander, washed twice with sterile water to remove excess
$\mathrm{CaCL}_{2}$, and stored in sterile glass bottles at $4^{\circ} \mathrm{C}$.

After preparation, pellets were viewed under a compound microscope as squash mounts to observe numbers of incorporated
ascospores. Pellets also were plated onto PDA or MA to confirm viability of the LE the mycoparasite in soil and its ability to or blank pellets.

potato dextrose agar (PDA) or mycological contents of five petri plates ( 100 by 15

Table 2. Survival and biomass of watermelon plants treated with Sphaerodes retispora var. retispora (isolate LE) and grown in soils artificially-infested with Fusarium oxysporum f. sp. niveum ${ }^{\mathrm{y}}$

\begin{tabular}{|c|c|c|c|c|c|c|}
\hline \multirow[b]{2}{*}{ Treatment $^{\mathrm{z}}$} & \multicolumn{2}{|c|}{ Method \#2 } & \multicolumn{2}{|c|}{ Method \#3 } & \multicolumn{2}{|c|}{ Method \#4 } \\
\hline & Mortality (\%) & Dry wt (g) & Mortality (\%) & Dry wt (g) & Mortality (\%) & Dry wt (g) \\
\hline Control & $0.0 \mathrm{a}$ & $1.35 \mathrm{a}$ & $0.0 \mathrm{a}$ & $2.0 \mathrm{a}$ & $0.04 \mathrm{a}$ & $1.32 \mathrm{a}$ \\
\hline Pathogen only & $25.0 \mathrm{~b}$ & $0.18 \mathrm{c}$ & $66.6 \mathrm{c}$ & $0.40 \mathrm{c}$ & $50.0 \mathrm{~b}$ & $0.26 \mathrm{c}$ \\
\hline LE + pathogen & $0.0 \mathrm{a}$ & $0.61 \mathrm{~b}$ & $25.0 \mathrm{ab}$ & $1.70 \mathrm{a}$ & $0.04 \mathrm{a}$ & $0.86 \mathrm{~b}$ \\
\hline LE/96-14 + pathogen & $0.0 \mathrm{a}$ & $0.39 \mathrm{c}$ & $25.0 \mathrm{ab}$ & $0.84 \mathrm{~b}$ & $58.3 \mathrm{~b}$ & $0.47 \mathrm{c}$ \\
\hline $96-14+$ pathogen & $50.0 \mathrm{~d}$ & $0.19 \mathrm{c}$ & $41.6 \mathrm{bc}$ & $0.37 \mathrm{c}$ & $58.3 \mathrm{~b}$ & $0.22 \mathrm{c}$ \\
\hline Blank pellets + pathogen & $33.3 \mathrm{c}$ & $0.21 \mathrm{c}$ & $41.6 \mathrm{bc}$ & $0.54 \mathrm{bc}$ & $58.3 \mathrm{~b}$ & $0.28 \mathrm{c}$ \\
\hline
\end{tabular}

y Average of 24 plants (2 plants per replication). Means followed by the same letter in a column are not significantly different according to Fisher's least significant difference test $(P=0.05)$. Method $2=$ root dip plants with treatment suspensions $\left(250\right.$ to 300 ascospores $/ \mathrm{ml}$ or $1 \times 10^{6} \mathrm{conidia} / \mathrm{ml}$ for LE and $96-14$, respectively) before transplantation; method $3=$ mix pellet treatments in potting soil $(5 \mathrm{~g}$ per 1 liter of mix), and grow plants for 6 weeks before transplantation; method $4=$ mix pellet treatments into pathogen-infested soils ( $5 \mathrm{~g}$ per $300 \mathrm{~g}$ of soil) and transplant with healthy plants. All treatments involved transplantation of watermelon plants into pathogen-infested soils (250 propagules/g of soil), except the control treatment.

${ }^{\mathrm{z}}$ Pathogen $=$ Fusarium oxysporum $\mathrm{f}$. sp. niveum, $\mathrm{LE}=$ Sphaerodes retispora var. retispora, $96-14=$ nonpathogenic isolate of $F$. oxysporum. contaminants. This same procedure was were evaluated after encapsulation into sodium alginate pellets. Other pelleted treatments used later in these studies included a nonpathogenic $F$. oxysporum iso(96-14), isolate 96-14 combined with microorganisms included in the alginate suspension. retispora var. retispora isolate $L E$. Four greenhouse to inoculate wate with the mycoparasite and evaluate its potential for reducing Fusarium wilt (Tables 1 and 2). Method \#1 consisted of ining alginate pellets treated with the rate of $5 \mathrm{~g}$ (pellet wet weight) to 1 liter of potting soil (wt:vol). Seedling trays were filled with this mixture and one watermelon seed (cv. Charleston Gray) was weeks (two to three true leaves), removed from cells, and roots were washed free of the soilless medium. Plants then were challenged with the pathogen by dipping roots into a $F$. oxysporum f. sp. $\left(1 \times 10^{6}\right.$ conidia/ml $)$. Isolate CSI-24 is a moderate-weak race 1 pathogen, was origipressive research plot in Leesburg, FL, and study. Pathogen-inoculated plants were transplanted into 1-gal plastic pots filled with the same peat-based, soilless medium three plants per replication per pot).

method \#1 was evaluated included four treatments: (i) untreated control, (ii) pathogen-inoculated control, (iii) inoculated with LE only, and (iv) inoculated with LE. The assay was chalonce (assays 1a and 1b; Table 1) After promising results were obtained from these assays, the concept was expanded with a second assay consisting of seven treatments, including: (i) untreated control, (ii) isolate and to monitor for the presence of

Methods for inoculating plants with $S$ nally isolated from a watermelon wilt-sup- 
LE-only control, (iii) pathogen-only control, (iv) inoculated with LE, (v) inoculated with LE and 96-14, (vi) inoculated with 96-14, and (vii) blank pellets with no microorganisms. All treatments except numbers $i$ and ii were challenged with the pathogen afterward by dipping treated roots into an $F$. oxysporum microconidial suspension and transplanted as described for assays $1 \mathrm{a}$ and $1 \mathrm{~b}$. After growing 8 weeks in the greenhouse, the inoculated plants from both assays were removed from media, roots were washed, and samples were air dried in paper bags and weighed for total biomass. The nonpathogenic $F$. oxysporum $96-14$ with isolate LE was included because of the inability of isolate LE to produce vigorous growth in the absence of $F$. oxysporum in initial lab isolations and assays $(8,11)$.

The remaining three inoculation methods (\#2, \#3, and \#4) included similar experimental practices. The same six treatments were used in all three as those described above from the second assay of method \#1, minus the LE-only control (Table 2). Method \#2 used plants grown in soilless mix for 6 weeks (two- to three-leaf stage). Roots were washed free of potting mix, then dipped into the various biological control suspensions. Suspensions used for inoculations included 250 to 300 ascospores $/ \mathrm{ml}$ for isolate $\mathrm{LE}$ and $1 \times 10^{6}$ microconidia/ml for 96-14. Inoculated plants were transplanted into $10-\mathrm{cm}$ clay pots (two plants/pot) containing noncultivated, unsterilized field soils artificially infested with $F$. oxysporum f. sp. niveum at approximately 250 propagules per gram of soil. Infestation levels of the pathogen were estimated from soil dilution plating of stock soil on Komada's medium (19). After 8 weeks, survival was recorded and the remaining watermelon plants were removed, dried, and weighed.

Inoculation method \#3 consisted of the same six treatments except that alginate pellets were used to deliver the mycoparasite and nonpathogenic F. oxysporum treatments. Watermelon plants were inoculated with isolate LE as described before by planting seed in soilless media amended with alginate pellets. After 6 weeks, plants were removed and transplanted into clay pots with infested field soil as described

Table 3. Survival and biomass of watermelon plants treated with Sphaerodes retispora var. retispora (isolate LE) and grown in soils naturally-infested with Fusarium oxysporum f. sp. niveum ${ }^{\mathrm{y}}$

\begin{tabular}{lcc}
\hline Treatment $^{\mathbf{z}}$ & Mortality (\%) & Plant dry weight (g) \\
\hline Naturally infested pathogen control & $95.8 \mathrm{~d}$ & $0.19 \mathrm{c}$ \\
Isolate LE alone + pathogen & $29.2 \mathrm{a}$ & $1.29 \mathrm{a}$ \\
Isolate LE + 96-14 + pathogen & $58.3 \mathrm{bc}$ & $0.86 \mathrm{ab}$ \\
96-14 alone + pathogen & $70.8 \mathrm{~cd}$ & $0.79 \mathrm{~b}$ \\
\hline
\end{tabular}

y Average of 24 plants ( 2 plants per replication). Means followed by the same letter are not statistically different according to Fisher's least significant difference test $(P=0.05)$.

${ }^{\mathrm{z}}$ Treatments were sodium alginate pellets containing isolate LE, 9614 (nonpathogenic isolate of $F$. oxysporum f. sp. niveum), or both and mixed into soils naturally infested with the Fusarium wilt pathogen ( $5 \mathrm{~g}$ of pellets per $300 \mathrm{~g}$ of soil) except the control. Infested pots were watered daily for 1 week prior to transplantation with healthy 6-week-old watermelon plants. with alginate pellets containing isolates LE and 96-14. Treatments were watered as necessary to maintain plant turgor. After 2 months, plants were removed and roots were washed and plated on PDA or MA amended with a liquid culture filtrate of $F$. oxysporum f. sp. niveum $(9,10,12)$ to determine if isolate LE could be recovered from watermelon roots. The entire root system (both tap and feeder roots) was cut into 1-cm-length pieces and plated (five pieces per plate) onto five replicate plates for each plant/pot.

The same nonsterile field soils were infested with alginate pellets containing isolate LE to determine its survival over time. This mycoparasite-infested field soil was then put into clay pots, and half of the infested soil was sown to watermelon while the other was left fallow. To mimic the normal time period between watermelon plantings in central Florida, pots were maintained in a walk-in growth chamber for a period of 9 months (June to February). Fallow pots were watered each time the pots planted with watermelons were watered. After 10 weeks, watermelon plants were removed and pots from both treatments were allowed to sit fallow for the remainder of the 9-month period. Temperature in the chamber was maintained at 25 to $30^{\circ} \mathrm{C}$, with an interval of light and dark cycles set at $12 \mathrm{~h}$ for the entire 9month period.

To determine survival of isolate LE in soil after 9 months, soil dilutions from each pot were performed and plated to either PDA or MA (10 replications/pot). Because of the faster growth of various soil

Table 4. Evaluation of Sphaerodes retispora var. retispora (isolate LE) to affect soil populations of Fusarium oxysporum f. sp. niveum with and without watermelon plants grown in soils

\begin{tabular}{l|c}
\hline Treatment & $\begin{array}{c}\text { Mean } \\
\text { propagule } \\
\text { counts }^{\mathbf{z}}\end{array}$ \\
\hline Pathogen + isolate LE (with) & $293.20 \mathrm{ab}$ \\
Pathogen + isolate LE (without) & $279.96 \mathrm{ab}$ \\
Pathogen alone (with) & $248.00 \mathrm{~b}$ \\
Pathogen alone (without) & $236.80 \mathrm{~b}$ \\
\hline
\end{tabular}

y Treatments with and without plants. Pathogen $=F$. oxysporum f. sp. niveum infested in soils at 250 propagules per gram of soil. Isolate LE $=S$. retispora var. retispora mixed into soils at $5 \mathrm{~g}$ of pellets per $300 \mathrm{~g}$ soil. Those treatments with plants were sown with watermelon seed, cv. Crimson Sweet (1 per pot), and maintained for the duration of the experiment.

${ }^{z}$ Average number of $F$. oxysporum f. sp. niveum colonies formed on Komada's medium after dilution plating of infested soils and 3 months of incubation in the greenhouse. Each value is the mean of 100 plates per treatment $(10$ plates per replication). Means followed by the same letter are not significantly different according to Fisher's least significant difference test $(P$ $=0.05$ ). 
saprophytes, a special dilution-plating technique was attempted to more readily detect $S$. retispora var. retispora (24). Soil samples were suspended in $50 \%$ ETOH and stirred for $5 \mathrm{~min}$. The suspension (1 $\mathrm{ml}$ ) was pipetted into plates before the addition of molten media. After solidification, plates were incubated at $40^{\circ} \mathrm{C}$ for 24 $\mathrm{h}$ before being transferred to an incubator maintained at $18^{\circ} \mathrm{C}(24)$.

To evaluate the potential influence of isolate LE on F. oxysporum f. sp. niveum soil populations, clay pots were filled with F. oxysporum f. sp. niveum-infested soil (250 propagules/g) and mixed with isolate LE incorporated into alginate pellets $(5 \mathrm{~g}$ per $300 \mathrm{~g}$ of soil). and maintained in the greenhouse. Control treatments consisted of pathogen-infested soils without isolate LE-treated pellets. Two other treatments were included which involved using the same two soil amendments, but were sown with watermelons. Changes in $F$. oxysporum $\mathrm{f}$. sp. niveum population levels in treated soils were determined by dilution plating on Komada's medium after 3 months of incubation in the greenhouse (19).

All experiments (biological control inoculation methods and ecological studies) utilized treatments arranged in a completely randomized design with six replications (pots) per treatment, and all experiments were repeated once, with the exception of assay two of inoculation method \#1. All collected data were subjected to the general linear model procedure. Treatment means were separated by Fisher's least significant difference test, and variance between repeated experiments was additionally analyzed for homogeneity.

\section{RESULTS}

Sodium alginate pellets. The sodium alginate pellets were an efficient technique for inoculation with $S$. retispora var. retispora. Fungal germination and growth of the mycoparasite occurred whenever pellets were plated onto media. Although viability of the isolate within the pellet was determined to be at least 2 months under refrigeration, biological activity was not tested after this period, and new batches of pellets were produced. Examination of pellets in squash mounts averaged 10 to 15 ascospores per field of view using the $\times 10$ power objective. A similar number of ascospores consistently was observed with each batch of pellets, provided that the LE cultures used were the same age (2 to 3 weeks).

Inoculation methods for $S$. retispora var. retispora isolate LE. None of the plants died after using inoculation method $\# 1$, but there were significant differences in total dry biomass (Table 1). Watermelon plants inoculated with isolate LE alone and not challenged with the pathogen were not adversely affected by the mycoparasite, because those treatments produced dry weights equal to those of the untreated controls from both assays (Table 1). Since no deleterious effects were observed on plants after inoculation with isolate LE singly, this treatment was omitted from subsequent inoculation methods. The LE + pathogen treatment had significantly higher dry weights than the pathogen-inoculated control treatment in all experiments employing this method. The second assay using this inoculation method included three new treatments that were added to preliminarily evaluate techniques for future experiments. The addition of the nonpathogenic isolate 96-14 and blank pellets in assay 2 had no beneficial effect on disease reduction. Plant dry weights using these treatments were no different than the pathogen-inoculated control (Table 1).

Three additional methods for inoculation with isolate LE were developed that evaluated these additional treatments, but employed $F$. oxysporum f. sp. niveuminfested soils as the challenge inoculum rather than microconidial suspension. These additional methods were designed to more realistically measure mycoparasite performance in a field situation (Table 2). Unlike inoculation method \#1, methods \#2, $\# 3$, and \#4 resulted in plant mortality ranging from $0 \%$ in untreated controls to $66 \%$ in pathogen-inoculated controls (Table 2). However, the total biomass produced from these methods was similar to that from method \#1. Treatments from method \#3 produced dry weights from the LE-inoculated treatment that were no different than those from the untreated control. Methods \#2 and \#4 resulted in dry weights from the LE treatments that were intermediate between the untreated and pathogen-inoculated controls.

The three treatments involving blank pellets or isolate 96-14 alone again did not reduce disease or increase plant biomass when compared with the pathogen-only treatment (Table 2). The combination treatment (LE and 96-14) had plant mortality similar to the LE-inoculated treatment in inoculation methods \#2 and \#3, but did not improve plant dry weights as consistently as did the LE-inoculated treatments. Regardless of the inoculation method employed, the combination treatment of LE and 96-14 did not improve plant response to disease over that of isolate LE alone (Table 2).

Evaluation of $S$. retispora var. retispora isolate $\mathrm{LE}$ in naturally infested soil. The results from this experiment were very similar to those using the artificially infested soils. The mycoparasite LE significantly reduced watermelon mortality and increased plant dry weights grown in soil naturally infested with $F$. oxysporum f. sp. niveum (Table 3 ). Treatments including $F$. oxysporum isolate $96-14$ provided no additional disease reduction compared with isolate LE alone. Isolate 96-14 did not reduce plant mortality compared with the naturally infested control, but did significantly improve plant dry weights (Table 3 ).

Ecological studies with $S$. retispora var. retispora isolate LE. In root colonization tests, isolate LE never was recovered in culture from watermelon roots that were grown in LE-treatments alone. It was, however, isolated in association with all treatments including $F$. oxysporum isolate 96-14. Isolate 96-14 rapidly grew from plated roots within several days. The mycoparasite was observed growing in the Fusarium cultures 10 to 14 days later. These results suggest that isolate LE did not colonize watermelon roots, but did colonize isolate $96-14$ as it grew on the roots.

In soil survival assays, isolate LE was recovered from soil dilutions after 9 months (data not shown). A selective or semiselective medium was not available for $S$. retispora var. retispora; therefore, a modified technique was attempted to more easily identify the mycoparasite from soils (24). This effort did help to reduce the incidence of rapidly growing soil saprophytes. However, it was not sufficient for obtaining quantitative values from mycoparasite propagules (ascospores or bulbils and hyphal fragments). Nevertheless, the parasite always was identified after dilution plating from soils in association with other microorganisms found inhabiting the unsterilized field soils, primarily $F$. oxysporum. This demonstrated that the ascospores of isolate LE remained viable for at least 9 months in the growth chamber after being artificially infested into field soils.

Colony counts for $F$. oxysporum f. sp. niveum estimated from dilution plating without isolate LE were similar to those originally applied to the soils (250 propagules/g; Table 4). The pathogen propagule counts estimated after being treated with isolate LE were not lower than the original controls, suggesting that LE was not reducing Fusarium propagules in soils. Furthermore, the presence or absence of watermelon plants grown in the infested soils had no effect on any of the colony counts from dilution plating (Table 4).

With the exception of assay 1 from inoculation method \#1, variance between repeated experiments was homogenous, and no treatment-experiment interactions were observed. Therefore, results from assay 1 (1a and 1b) of method \#1 are presented separately (Table 1). The results of all other repeated experiments have been combined (Tables 2-4).

\section{DISCUSSION}

The idea of using mycoparasites as biological control organisms for plant pathogens was first suggested by Weindling in 1932 after he observed that Trichoderma lignorum was capable of parasitizing several diverse soilborne fungi in culture, including Rhizoctonia solani, Phytoph- 
thora parasitica, Pythium spp., Rhizopus spp., and Sclerotium rolfsii (33). Since that time, many mycoparasites have been tested in this capacity, but few have provided economical control of soilborne plant diseases. This is due primarily to the high rate of mycoparasite application required, and low levels of control achieved (1).

The most successful examples of biological control of Fusarium wilt diseases utilizing mycoparasites have consistently been demonstrated with the use of nonpathogenic $F$. oxysporum isolates, often found initially occurring in suppressive soils $(2-4,16,20,21)$. The mechanism of suppression and disease reduction is mainly attributed to an effect similar to cross protection, or induced resistance in host plants prior to infection by the pathogen $(4,20,21)$. The watermelon wilt-suppressive research plots in Florida have been documented to contain higher levels of various microorganisms, including nonpathogenic isolates of $F$. oxysporum, bacteria, and actinomycetes than the corresponding wilt-conducive plots (21). It was further shown that the mechanism of suppression in these plots was due to a protective resistance induced by saprophytic isolates of $F$. oxysporum that infected plants more rapidly than pathogenic isolates $(20,21)$.

The attempt to use Sphaerodes retispora var. retispora (isolate LE) as a biological control agent is unprecedented. It is a unique organism for this purpose because it does not possess many of the ideal biological traits characteristic of the more successful mycoparasites such as Trichoderma or Gliocladium spp. $(1,4,25,30)$. Isolate LE does not compete well in culture with other organisms, and exhibits a nutritional dependency upon isolates of $F$. oxysporum for rapid growth and sporulation (8). Furthermore, it does not produce massive numbers of functional conidia, but does form bulbils and ascospores homothallically $(8,10)$. Its potential for survival in soil is apparently adequate, but the fate of individual propagules added to soil or plant root systems is unknown.

Sodium alginate pellets have been successfully deployed on a number of occasions for the introduction of biocontrol agents in the attempt to protect crops from soilborne pathogens $(8,22,23)$. The alginate pellet method also effectively introduced the mycoparasite $S$. retispora var. retispora into the experimental system used in this study. The same relative number of ascospores was consistently observed after pellet formation, and viability and survival of the fungus also was consistently demonstrated after isolation from infested soils.

Regardless of the inoculation method evaluated, this study has provided evidence that the $S$. retispora var. retispora isolate used has the potential to reduce watermelon mortality and increase plant biomass compared with Fusarium wilt pathogeninoculated controls at the greenhouse level. The use of isolate LE by itself was significantly better than the pathogeninoculated control for decreasing numbers of dead plants and increasing plant biomass in all experiments (Tables 1 and 2). The use of LE also resulted in disease reduction that was either equal to untreated controls or intermediate between pathogen and untreated controls (Tables 1 and 2). However, the mechanism for reducing wilt disease development by isolate LE is unknown. The combination of isolates LE and the nonpathogenic $F$. oxysporum isolate 96-14 was not as consistent in reducing numbers of dead plants or increasing dry weights as with isolate LE alone. This is somewhat surprising because this treatment was expected to help improve distribution of the parasite by first colonizing a fungus having the ability to better compete with the pathogen in the rhizosphere. It also demonstrates that isolate 96-14 provided no induced resistance for protecting plants against the wilt pathogen.

Inoculation method \#3, which exposed plants to the parasite via the potting mix at seeding followed by transplanting into pathogen-infested soils, would likely be the most efficient and practical technique for applying biocontrol agents into this system. Root-dipping all plants with parasite treatments prior to field transplantation is too labor intensive, and applying treated pellets directly into transplant beds in the field would likely require impractically high volumes of alginate pellets. The technique of combining parasites into planting mixes in the greenhouse is an efficient, inexpensive method of providing protection for developing plants, and is easily incorporated into vegetable production systems (including watermelon) in Florida. This technique has been successfully implemented with tomato, pepper, celery, and citrus using T. harzianum (29). Combining different antagonists or the integration of mycoparasitism with other technologies will also likely increase the efficiency or consistency of biological control as a viable disease management technique $(2,30)$.

It is still unknown as to whether isolate LE can effectively colonize watermelon roots without the additional presence of $F$. oxysporum. It was never isolated from inoculated roots by itself, but was successfully recovered in association with the nonpathogenic $F$. oxysporum 96-14 in greenhouse studies. It was also originally isolated in association with a pathogenic isolate of $F$. oxysporum f. sp. niveum $(8,9,10)$. Isolate $\mathrm{LE}$ was recovered from soils after 9 months, but only as part of a complex with other fungal organisms, not singly. These results indicated that the parasite could survive and regenerate after at least 9 months in soils. They also suggested that $S$. retispora var. retispora exhibits a dependency upon other organisms for germination and growth and is not itself an aggressive soil competitor.

Other ascomycetes closely related to Sphaerodes, such as Melanospora and Persiciospora, have been demonstrated to be parasitic on other fungi, including several Fusarium spp. (9-11,18,32). Species of Melanospora and their anamorphs are considered to be fusion biotrophs (17). These types of parasites prey upon their hosts without the production of cell walldegrading enzymes, and have been shown ultrastructurally to establish physical contact without penetration $(13,17)$. Membrane-lined channels similar to plasmodesmata are formed between fungal contact points, thus providing avenues for cytoplasmic exchange (13). Although not investigated here, it is presumed that the $S$. retispora var. retispora (isolate LE) used in this study functions in a manner similar to that of some of the more studied fusion biotrophic parasites, such as Melanospora damnosa (anamorph Gonatobotrys simplex $)$ or $M$. zamiae $(13,17,18,32)$. The isolate of Sphaerodes tested in this study does form contact branches and hook cells with Fusarium hyphal filaments $(8,11)$ identical to those described for $M$. zamiae (18).

Successful biological control demonstrated at the laboratory or greenhouse level often is not achieved in the field due to a number of interrelated environmental factors. Key among these factors is a thorough understanding of the ecological interactions and relationship between host and parasite. In order to obtain this type of information, the design and conduction of preliminary studies (8-11) are often necessary to more effectively eliminate or accelerate the selection of potential candidates for future biocontrol evaluations. This study has provided some practical evidence of disease control for Fusarium wilt of watermelon in the greenhouse that encourages expanded studies of $S$. retispora var. retispora and other related mycoparasites into field studies.

\section{ACKNOWLEDGMENTS}

We thank G. L. Benny, A. V. Ogram, G. W. Simone, and F. W. Zettler for suggestions, help, and advice throughout the course of this study.

\section{LITERATURE CITED}

1. Adams, P. B. 1990. The potential of mycoparasites for biological control of plant diseases. Annu. Rev. Phytopathol. 28:59-72.

2. Alabouvette, C., Lemanceau, P., and Steinberg, C. 1993. Recent advances in biological control of Fusarium wilts. Pestic. Sci. 37:365-373.

3. Alabouvette, C., Lemanceau, P., and Steinberg, C. 1996. Biological control of Fusarium wilts: opportunities for developing a commercial product. Pages 192-212 in: Principles and Practice of Managing Soilborne Plant Pathogens. R. Hall, ed. American Phytopathological Society Press, St. Paul MN.

4. Cook, R. J. 1993. Making greater use of microorganisms for biological control of plant pathogens. Annu. Rev. Phytopathol. 31:53-80. 
5. Cook, R. J., and Baker, K. F. 1983. The Nature and Practice of Biological Control of Plant Pathogens. American Phytopathological Society, St. Paul, MN.

6. Elmstrom, G. W., and Hopkins, D. L. 1981. Resistance of watermelon cultivars to Fusarium wilt. Plant Dis. 65:825-827.

7. Fravel, D. R., Marois, J. J., Lumsden, R. D., and Connick, W. J. 1985. Encapsulation of potential biocontrol agents in an alginate-clay matrix. Phytopathology 75:774-777.

8. Harveson, R. M. 1999. Evaluation of the parasitic relationship of Melanospora and other allied genera with Fusarium oxysporum. $\mathrm{Ph}$.D. thesis. University of Florida, Gainesville.

9. Harveson, R. M., and Kimbrough, J. W. 2000. First report of Persiciospora moreaui, a parasite of Fusarium oxysporum, in the western hemisphere. Mycotaxon 76:361-366.

10. Harveson, R. M., and Kimbrough, J. W. 2001. Identification of Melanospora and its allies from field isolations of Fusarium oxysporum. Int. J. Plant Sci. 162:403-410.

11. Harveson, R. M., and Kimbrough, J. W. 2001. Parasitism and measurement of damage to Fusarium oxysporum by species of Melanospora, Sphaerodes, and Persiciospora. Mycologia 93:249-257.

12. Harveson, R. M., and Rush, C. M. 1997. Genetic variation among Fusarium oxysporum isolates from sugar beet as determined by vegetative compatibility. Plant Dis. 81:85-87.

13. Hoch, H. C. 1977. Mycoparasitic relationships: Gonatobotrys simplex parasitic on Alternaria tenuis. Phytopathology 67:309314.

14. Hopkins, D. L., and Elmstrom, G. W. 1984. Fusarium wilt in watermelon cultivars grown in a 4-year monoculture. Plant Dis. 68:129-131.

15. Hopkins, D. L., Larkin, R. P., and Elmstrom, G. W. 1987. Cultivar-specific induction of soil suppressiveness to Fusarium wilt of watermelon. Phytopathology 77:607-611.

16. Hornby, D. 1983. Suppressive soils. Annu. Rev. Phytopathol. 21:65-85.

17. Jeffries, P., and Young, T. W. K. 1994. Interfungal Parasitic Relationships. CAB International, Wallingford, UK.

18. Jordan, E. G., and Barnett, H. L. 1978. Nutrition and parasitism of Melanospora zamiae. Mycologia 70:300-312

19. Komada, H. 1975. Development of a selective medium for quantitative isolation of Fusarium oxysporum from natural soil. Plant Prot. Res. 8:114-125.

20. Larkin, R. P., Hopkins, D. L., and Martin, F. N. 1993. Ecology of Fusarium oxysporum $\mathrm{f}$. sp. niveum in soils suppressive and conducive to Fusarium wilt of watermelon. Phytopathology 83:1105-1116.

21. Larkin, R. P., Hopkins, D. L., and Martin, F. N. 1996. Suppression of Fusarium wilt of watermelon by nonpathogenic Fusarium oxysporum and other microorganisms recovered from a disease-suppressive soil. Phytopathology 86:812-819.

22. Lewis, J. A., and Papavizas, G. C. 1985. Characteristics of alginate pellets formulated with Trichoderma and Gliocladium and their effect on the proliferation of the fungi in soil. Plant Pathol. 34:571-577.

23. Lewis, J. A., and Papavizas, G. C. 1987. Application of Trichoderma and Gliocladium in alginate pellets for control of Rhizoctonia damping-off. Plant Pathol. 36:438-446.

24. Malloch, D. 1970. The genera of cleistothecial ascomycota. Ph.D. thesis. University of Toronto, Toronto, Canada.

25. Marois, J. J., and Locke, J. C. 1985. Population dynamics of Trichoderma viride in steamed plant growth medium. Phytopathology 75:115-118.

26. Marois, J. J., and Mitchell, D. J. 1981. Effects of fumigation and fungal antagonists on the relationships of inoculum density to infection incidence and disease severity to Fusarium crown rot of tomato. Phytopathology 71:167170.

27. Martyn, R. D. 1996. Fusarium wilt of watermelon. Pages 13-14 in: Compendium of Cucurbit Diseases. T. A. Zitter, D. L. Hopkins, and C. E. Thomas, eds. American Phytopathological Society, St. Paul, MN.

28. Nelson, P. E. 1981. Life cycle and epidemiology of Fusarium oxysporum. Pages 51-80 in: Fungal Wilt Diseases of Plants. M. E. Mace, A. A. Bell, and C. H. Beckman, eds. Academic Press, New York.

29. Nemec, S., Datnoff, L. E., and Strandberg, J. 1996. Efficacy of biocontrol agents in planting mixes to colonize plant roots and control root diseases of vegetables and citrus. Crop Prot. 15:735-742.

30. Papavizas, G. C. 1985. Trichoderma and Gliocladium: Biology, ecology, and potentia for biocontrol. Annu. Rev. Phytopathol. 23:23-54

31. Smith, E. F. 1894. The watermelon disease of the South. Am. Assoc. Adv. Sci. Proc. 43:289 290.

32. Vakili, N. G. 1989. Gonatobotrys simplex and its teleomorph, Melanospora damnosa. Mycol. Res. 93:67-74.

33. Weindling, R. 1932. Trichoderma lignorum as a parasite of other soil fungi. Phytopathology 22:837-845. 